\title{
EMPRESAS PÚBLICAS EN AMÉRICA LATINA: HISTORIA, CONCEPTOS, CASOS Y PERSPECTIVAS*
}

\author{
Guillermo Guajardo Soto \\ Centro de Investigaciones Interdisciplinarias en Ciencias y Humanidades \\ Universidad Nacional Autónoma de México, México \\ guillermo.guajardo@unam.mx
}

\begin{abstract}
RESUMEN
El artículo destaca la necesidad de abordar la historia de la empresa pública latinoamericana por haber cumplido un papel relevante en el desarrollo de la región durante el siglo XX, pero también por la actual re-emergencia de este tipo de organismos en el sector energético internacional, seguir cumpliendo en muchos países un papel estratégico y finalmente porque tras décadas de privatizaciones hay una débil memoria colectiva sobre estos organismos, predominando la versión neoliberal que justificó la venta del acervo público. ¿Conocemos bien la historia sobre la importancia y trayectoria de las empresas públicas en México y América Latina? ¿Qué explica su resistencia tras décadas de privatizaciones? Estas preguntas se responden en este dossier de la Revista de Gestión Pública, que reúne un grupo de trabajos que analizan los casos de Uruguay, Costa Rica, Bolivia, Brasil y Argentina entre 1912 y 2012, dando luces sobre las actividades empresariales del Estado bajo distintos modelos económicos. En esos países las empresas públicas se han ubicado en sectores básicos para el funcionamiento de las economías, como telecomunicaciones, electricidad, petróleo, transportes $y$, en menor medida manufacturas. En la última sección se hace una invitación no sólo a la lectura sino a iniciar una agenda de análisis que permita develar la compleja historia de estos organismos públicos.
\end{abstract}

Palabras clave: Empresas públicas, América Latina, Historia, Economía.

* Agradezco a Alejandra Pech su colaboración en la revisión final de este volumen. 


\title{
PUBLIC COMPANIES IN LATIN AMERICA: HISTORY, CONCEPTS, CASES AND PERSPECTIVES
}

\begin{abstract}
The article highlights the need to address the history of public companies in Latin America for having played a significant role in regional development during the 20th Century, as well as for the current reappearance of these organisms in the international energy sector, for the strategic role they still play in many countries and, lastly, because decades of privatization have weakened the collective memory on these organisms, in favour of the prevailing neoliberal version which justified the sale of the public heritage. Do we have good knowledge on the history behind the importance and track record of public companies in Mexico and Latin America? How can their resistance after decades of privatizations be explained? These queries are replied in the current dossier of the Public Management Journal, which gathers a group of studies analysing the cases of Uruguay, Costa Rica, Bolivia, Brazil and Argentina between 1912 and 2012, shedding light on the entrepreneurial activities of the State under different economic models. In these countries, public companies have placed themselves in vital areas for the functioning of the economies, such as telecommunications, electricity, oil, transportation and, to a lesser extent, manufacturing. The final section is an invitation not only to read but also to initiate an agenda to analyse and allow revealing the complex history of these public organisms.
\end{abstract}

Keywords: Public companies, Latin America, History, Economy. 


\section{LA EMPRESA PÚBLICA LATINOAMERICANA EN PERSPECTIVA HISTÓRICA}

La historia de la intervención estatal en América Latina, a pesar de haber sido clave en el desarrollo de la región, hoy en día presenta lagunas notables sobre el papel y trayectoria de las empresas públicas en el siglo XX, tema que debe ser retomado por varias razones. La primera es por la reemergencia de las empresas estatales en el sector energético internacional, especialmente en petróleo, gas y electricidad. La segunda es la evidencia empírica que indica que en la región latinoamericana las empresas públicas siguen cumpliendo un papel relevante en sectores estratégicos, al igual que en Asia y Europa. Finalmente, una tercera razón es que tras décadas de privatizaciones actualmente hay una débil memoria colectiva sobre estos organismos, predominando la versión neoliberal que justificó la venta del acervo público. Todo esto nos plantea algunas gruesas interrogantes. ¿Conocemos bien la historia sobre la importancia y trayectoria de las empresas públicas en México y América Latina? ¿Qué explica su resistencia tras décadas de privatizaciones? Para responderlas en este dossier de la Revista de Gestión Pública, que nos correspondió coordinar, se ha reunido un grupo de trabajos que tratan sobre fenómenos transversales a buena parte de América Latina entre 1912 y 2012, dando luces sobre las diversas actividades empresariales del Estado dentro de los distintos modelos económicos que se han aplicado en la región.

Una característica común en los artículos que tratan sobre Uruguay, Costa Rica, Bolivia, Brasil y Argentina es que las empresas públicas se han ubicado en sectores básicos para el funcionamiento de las economías, como telecomunicaciones, electricidad, petróleo, transportes y, en menor medida manufacturas, ajustándose a una continuidad que hoy en día Christiansen (2011) logró establecer para los países integrantes de la Organización para la Cooperación y Desarrollo Económicos (OCDE), en donde las empresas públicas siguen siendo relevantes en sectores estratégicos para la competitividad empresarial como transporte, energía, finanzas y telecomunicaciones. Estas firmas además se caracterizan por ser de una gran escala en capital y grandes empleadores, ya que trabajan cerca de nueve millones de personas en empresas de propiedad directa y/o con participación minoritaria. Si bien globalmente la propiedad estatal ha disminuido, las empresas públicas han mantenido su importancia en muchos países (Christiansen 2011).

Desde un punto de vista histórico otra característica de estos organismos es que han actuado bajo diversos formatos socio-económicos e ideológicos, conservando una diferencia de fondo con las empresas privadas: una conducta a favor del interés público a la vez que operan como negocio, 
tensión que sigue presente y se encuentra en los orígenes del debate sobre la regulación y la propiedad pública, y que durante el siglo XX llevaron a un enfrentamiento falso entre capitalismo y socialismo. Tras el fin de la Guerra Fría y el avance de las políticas pro-mercado la tensión es mayor con respecto al ambiente, desempeño y organización de las empresas públicas; los enemigos de la intervención estatal hoy en día han reverdecido sus argumentos ante la conformación de un espectacular núcleo de trece grandes empresas públicas que controlan más de las tres cuartas partes de las reservas de petróleo del mundo. Un reciente llamado en contra de las empresas públicas fue hecho por el vocero histórico del liberalismo clásico, The Economist de Londres, que en el 2012 lanzó un número especial (Special Report: State Capitalism) para señalar que las empresas públicas representan 28 de las 100 mayores compañías del mundo emergente y, al igual que lo indica Christiansen, The Economist indicó que en China y Rusia la disminución del sector estatal se hizo como una poda selectiva en vez de la liberalización total, desprendiéndose los gobiernos de las pequeñas empresas y reforzando el control sobre los grandes; así, "Leviatán se está convirtiendo en un capitalista financiero, así como un capitán de industria" (The Economist 2012). A este respecto, Ian Bremmer, politólogo y fundador de Eurasia Group en su libro The End of the Free Market (2010) destacó que ha surgido un nuevo capitalismo de Estado en países como China, Rusia, los Estados Árabes del Golfo Pérsico, Irán, Venezuela y otros, liderado por empresas públicas que ejercen un gran dominio de los mercados y que son un desafío tanto para la competitividad de Estados Unidos como para toda la economía global.

Sin embargo, Aldo Musacchio y Sergio G. Lazzarini en su libro Leviathan Evolving (en prensa por Harvard University Press) ${ }^{1}$ revelan que en América latina este nuevo capitalismo tiene presencia por el rechazo popular a las privatizaciones y también porque adopta formas distintas a las practicadas entre los decenios de 1930 a 1980. Ya no se trata del dilema planteado por Klapp (1982) con respecto a la intervención del Estado en la explotación del petróleo en la década de 1970, entre ser propietario o empresario, sino que para estos autores el antiguo "Leviatán empresario" que fue desmantelado por las privatizaciones ha sido reemplazado por un Leviatán que es inversionista mayoritario o bien minoritario, siendo esta última forma la que se presenta con un mejor desempeńo.

Llegados a este punto conviene repasar los argumentos, ya históricos, en contra de las empresas públicas y que fueron sintetizados por Robert Millward (2005): 1) escaso o débil incentivo para los mecanismos de

I Agradezco a Aldo Musacchio compartir el manuscrito del libro que, al momento de escribir este texto, se encuentra en prensa. 
monitoreo de su manejo y desempeño; 2) asimetrías en la información entre gerentes y propietarios para la verificación empírica del deterioro del desempeño de una gran firma por acciones; 3) la regulación de las empresas públicas ha sido caracterizada por algunos economistas como un proceso en donde éstas más bien tienden a capturar al regulador; 4) las teorías de la decisión pública caracterizan a los servidores públicos como maximizadores de su propia utilidad más que motivados por actuar como funcionarios desinteresados; 5) finalmente, de acuerdo al enfoque austriaco, los costos económicos y costos de oportunidad son esencialmente subjetivos, los funcionarios públicos no pueden comprometerse significativamente en idear esquemas de precios basados en los costos y en la reglas de inversión para el sector público.

Considerando el marco anterior debe señalarse que en América Latina el recorte al sector público llevado a cabo desde la década de 1980 fue indiscriminado y se ajustó al quinto argumento indicado por Millward (2005). Esto fue muy claro en Argentina con la venta completa del sector energético y de telecomunicaciones. México vendió el monopolio telefónico a un solo operador privado y en la década de 1990 cerró los servicios ferroviarios de pasajeros con la consecuencia de que hoy en día no existe un operador estatal, ni activos, ni personal directivo, ni de planeación para implantar un nuevo sistema de transporte masivo. El caso de Chile es el ejemplo más difundido de cómo los imperativos ideológicos de la Guerra Fría impulsaron, tras el golpe militar de 1973, una masiva privatización y cierre de cientos de empresas públicas dentro de un marco autoritario ${ }^{2}$.

No obstante hoy en día se están generando las condiciones para una nueva agenda de investigación y difusión de resultados sobre la trayectoria histórica, los factores de creación y desempeño; la evidencia indica que el origen ideológico de las empresas públicas ha sido indistinto, abarcando desde la izquierda a la derecha. Que sus factores de creación fueron múltiples, como la protección del mercado interno, las subvenciones al sector privado, el suministro de servicios, el fomento del crecimiento y la capacidad de recaudar recursos frescos sin recurrir a impuestos directos. Parte de estas temáticas son las que se presentan en este dossier y que queremos ubicar dentro de un marco de tiempo y debates sobre el origen y las tareas de las empresas públicas. En la última sección unimos los distintos casos para conciliar la historia, la economía y la administración pública

2 Para entender la historia del proceso de privatización chileno, véase Gárate (2012) 


\section{MERCADO Y ESTADO: ENTRE LAS ETAPAS DEL DESARROLLO Y LA FRACASOMANÍA}

Privatización y cierre de empresas públicas en América Latina en las últimas tres décadas fueron parte una transformación radical que cubrió las relaciones entre Estado, economía y el sistema político. Esto fue producto de un consenso de los defensores del mercado, muchos de los cuales se habían formado en las escuelas de economía de los Estados Unidos, en particular en la Universidad de Chicago, sede de una vigorosa tradición de individualismo liberal que desarrolló teorías económicas que justificaban las soluciones del mercado para los problemas de política económica, aplicando una conocida receta desde Adam Smith: más laissez-faire. En particular se revitalizó la crítica planteada en 1944 por Friedrich Hayek en su libro Camino de servidumbre, de identificar a la tiranía con la planificación y la intervención pública, criticas que se unificaron con las de Smith de un orden social espontáneo para establecer los fundamentos de la "contrarrevolución monetaria" opuesta al papel del Estado en la economía (Deane 1993: 194, 197, 200). La aplicación de esa receta desmontó las bases institucionales que desde las décadas de 1930 y 1940 habían sostenido el crecimiento económico regional, especialmente de la industrialización sustitutiva de importaciones (ISI), estrategia que entre los decenios de 1950 a 1970 contribuyó en forma notable al crecimiento económico de la región, alcanzando una tasa de 5,5\% anual, superior al 1,2\% de los años ochenta y al 3,1\% de 1990-1996 (French-Davis 1997: 159). Pero también desde la década de 1970, empezó un ciclo de agotamiento que se expresó en el incremento de la inflación, dándose paso a medidas de estabilización dentro de un marco de proyectos ideológicos enfrentados. En su primera versión, monetarista, las medidas se implementaron a mediados de la década de 1970 en Chile, México y Argentina, para institucionalizarse desde la década de 1990 con la era neoliberal.

El neoliberalismo escaló desde las medidas de control de la inflación hacia una ortodoxia: el predominio del mercado sobre las soluciones de intervención estatal y una nueva inserción en la economía mundial. Tomó fuerza cuando América Latina debió enfrentar altas tasas de inflación y desde 1982 cuando se elevó el costo de la deuda externa. Las medidas para lograr un equilibrio financiero interno y un balance en las cuentas externas alteraron el tamaño, función y naturaleza del Estado, abriéndose un nuevo patrón de desarrollo centrado en el liderazgo de la inversión privada y en las señales del mercado (Torre 1998: 122). Esto cuajó en el recetario tecnocrático del llamado Consenso de Washington, que John Williamson identificó como un conjunto de medidas de política económica de estilo neoclásico sobre el contenido y la secuencia de las reformas 
macroeconómicas y de estabilización, las cuales se propagaron a través de la supervisión del Banco Mundial y del Fondo Monetario Internacional (FMI) (Waterbury 1999: 323-341 y Rodrik 1996: 9-41). Lo que vino después, a juicio de Joseph Stigliz, fue una visión parcial, ortodoxa y de corto plazo de los hacedores de política latinoamericanos, patrón de conducta que, en todo caso, ya había sido indicado décadas atrás por Albert $\mathrm{O}$. Hirschman, en el sentido que los hacedores de políticas latinoamericanas se planteaban un amplio abanico de reformas con crecientes grados de dificultad sin solucionar, primero, las etapas más sencillas antes de pasar a las más difíciles, dando como resultado una creciente frustración entre la realidad y las tareas propuestas (Stiglitz 2003: 7-40, Hirschman 1985: 88-89). Esta conducta Hirschman la llamó fracasomanía: desconocer el bagaje de experiencias transmitidas del pasado y la convicción de que todo lo hecho anteriormente ha sido un fracaso: "Cuando se llega a este punto, lo único que cabría hacer es importar del exterior cosas, actitudes, valores, sin intentar aprender de la propia experiencia” (Botto y Rojo 1996: 656). En ese sentido las tecnocracias latinoamericanas fueron más rígidas que sus mentores internacionales para aplicar las recetas de apertura comercial, desregulación y privatización, (Camp 1997: 165, Abel y Lewis 1985: 21 y Drake 1997:68), a la vez que lograron legitimarse con fuentes de prestigio internacional como el Fondo Monetario Internacional y el Banco Mundial. Sin embargo, como señala Nelson la visión anglosajona para solucionar problemas de coordinación de recursos y cambios, es un modelo de texto de una economía pura, ignorándose las condiciones políticas locales sin respetar la autodeterminación, tolerancia y neutralidad (Nelson 2002: 216, Williams 1999: 79-81, 89-90).

La escuela neoliberal de Chicago a inicios de la década de 1970 en los Estados Unidos era considerada una élite periférica y fanática opuesta al keynesianismo y a las visiones pragmáticas sobre las relaciones entre mercado y Estado. Esto es importante destacarlo porque en ese entonces había un consenso internacional bastante extendido a favor de las empresas públicas no sólo en el bloque socialista sino en el ámbito occidental, a diferencia de la ortodoxia que más tarde vendría. Incluso el término privatización, que fue planteado en la década de 1960 Peter F. Drucker (1969) en su libro The Age of Discontinuity, se empleaba para caracterizar el traspaso de ciertas actividades del Estado a una gestión de tipo privado sin que necesariamente fuera la venta completa del inventario público (Drucker 1988: 173).

Una visión de lo anterior -sorprendente- es la que en 1973 tenía el conocido economista estadounidense Walt Whitman Rostow, fallecido en el 2003 y popularmente conocido por su libro Las etapas del crecimiento 
económico (1960), quien era un ferviente anticomunista, promotor del capitalismo, de la libre empresa y Consejero de Seguridad Nacional durante la guerra de Vietnam, experiencia que plasmó en sus memorias (Rostow 2003). Rostow en 1973 fue invitado a Barcelona a una conferencia que tenía el llamativo título de la "Empresa pública versus empresa privada en economías en proceso de desarrollo". Indicó que en la historia moderna de Occidente nunca hubo sistemas económicos de puro laissez-faire y de haberlos tenido no se habrían satisfecho los propósitos de las sociedades. Agregó que la determinación de los límites entre lo público y lo privado debía darse de acuerdo los problemas que debían enfrentarse, algo avalado por la historia porque hasta ese entonces las relaciones entre la autoridad pública y la empresa privada habían sido de compañerismo y complementariedad. Tomó el caso mexicano como ejemplo de que la intervención del gobierno había contribuido a un extraordinario crecimiento tanto en tamaño como en influencia del comercio privado. Pero también destacó que era necesario un contrato social para evitar una explotación del trabajador para ampliar los beneficios y en ese sentido los gobiernos eran los llamados a negociar esos contratos sociales (Rostow 1973).

Considerando lo anterior, puede afirmarse que en el caso latinoamericano el programa de desregulación extrema y privatización de las empresas públicas fue único porque acabó con las unidades y rompió los pactos sociales existentes. Desde la década de 1980 las reformas alteraron el tamaño, función y naturaleza del Estado, a la vez que como lo señaló Torre (1998) disminuyó la influencia institucionalmente sancionada de los intereses sectoriales, recortando los compromisos fiscales y removiendo los arreglos corporativistas para desvincular la gestión del Estado del sistema político. Sin embargo, lo grave fue el despojo de capacidades que en las sociedades capitalistas contemporáneas son necesarias para soportar y arbitrar un gran número de cambios, capacidades que generalmente son públicas (Nelson 2002: 208). En Latinoamérica, esas habilidades históricamente han sido limitadas y las reformas neoliberales en muchos países las debilitaron notablemente o bien desmantelaron (Cole, Ohanian, Riascos y Schmitz 2005: 69-107) y una buena parte residía en las empresas públicas.

\section{UN BAZAR DE ORÍGENES, FORMATOS, DEFINICIONES Y TAREAS}

Lo planteado en la sección anterior nos señala que en el largo plazo, las modernas economías capitalistas han sido y siguen siendo una combinación de Estado y mercado, en donde las empresas públicas cumplen un papel fundamental en la provisión de infraestructura, energía y movilidad, y de una manera más secundaria en las manufacturas y en el sector de defensa. En la región latinoamericana, esto sigue siendo relevante en sectores como 
la minería, energía, transportes, distribución, telecomunicaciones y en la exportación de algunas materias primas.

Para autores como Millward (2005), Toninelli (2000), Bouneau y Fernandez (2004), Díaz-Fuentes y Comín (2004), el origen de las empresas públicas se encuentra en Europa en las manufacturas reales, astilleros y arsenales del Antiguo Régimen, y fue en el siglo XIX cuando surgió el perfil moderno de la empresa pública por el crecimiento de las infraestructuras, la industrialización y la urbanización. En el caso de América Latina, los factores de creación fueron la protección del mercado interno, las subvenciones al sector privado, el suministro de servicios, fomento del crecimiento o bien para recaudar recursos frescos sin recurrir a impuestos directos. Incipientes indicios de ello se dieron antes de 1914, apareciendo en forma consistente desde las décadas de 1930 y 1940 en los sectores de energía e infraestructuras, para expandirse en los decenios de 1960 y 1970 con la industrialización y la urbanización ${ }^{3}$.

Elavancedelaempresapúblicasedioadoptandounadiversidad deformatos y denominaciones como compañías, empresas, institutos, comisiones, entes, servicios, que conformaron un conjunto de establecimientos dependientes de organismos centralizados o descentralizados ya sea de la administración nacional, provincial y municipal. A este respecto, Georges Ribeill (2004: 29), al analizar las empresas y servicios franceses, destacó la amplia diversidad de formas organizativas, acumuladas y preservadas de monopolios estatales, empresas privadas concesionarias, sociedades de economía mixta, empresas nacionalizadas y otras que, históricamente, integran un amplio bazar de formas jurídicas, fuertemente eclécticas y poco coherentes. Esto obliga a comprender las complejidades de las relaciones reglamentarias y contractuales que están presentes tanto en el origen como en las interpretaciones divergentes sobre la naturaleza de la empresa pública, como también en su definición.

Algunas definiciones señalan que son públicas las firmas que van desde una participación accionaria del 10\% del capital, hasta los historiadores que consideran la evolución y taxonomía de los organismos públicos, última aproximación que queremos destacar. Así para Belini y Rougier (2008), tomando el caso de Argentina, emplean la noción abarcadora de "Estado empresario" para inscribir no sólo las entidades sino también las capacidades de impulso o sostenimiento de actividades tanto estatales como privadas en la economía. Más escéptica, aunque en elaboración por la dificultad de analizar caso por caso largas trayectorias, es nuestro enfoque y de otros

3 Para profundizar sobre este punto, véase Belini y Rougier (2008), Guajardo (2007), Marichal (2003), Casar y Peres (1998), Barenstein (1982) y Carrillo Castro (1976). 
autores sobre la necesidad de hacer una distinción entre empresa y servicio por la pérdida o adquisición de capacidades de negocios y de ganancias. Esto proviene de los resultados del estudio sobre los ferrocarriles estatales en Chile y México entre 1850 y 1950 (Guajardo 2007, 2010, Guajardo, Salas y Velázquez 2010): la Empresa de los Ferrocarriles del Estado en Chile, creada en 1884 y todavía existente, y Ferrocarriles Nacionales de México (Ferronales) formada en 1907 y que dejó de operar en 1997. Cuando se crearon, estas empresas cubrían sus gastos e inversiones, pero debido a motivaciones de distinto signo ideológico, ya sea las de un régimen oligárquico y o las de uno revolucionario, convergieron en entidades que no podían controlar sus gastos, registraban una contabilidad en números rojos y recibían inyecciones de capital público para sostener su operación y expansión sin retornos para el Estado. En particular, en el caso de Ferronales, empresa de capital público y privado, Riguzzi y Kuntz (1996), Grunstein (2008) y Guajardo (2010) han concluido que tras la Revolución mexicana y la incautación del gobierno, desde 1920 esta compañía sufrió un daño intangible dado por el reemplazo de los sistemas de méritos laborales por los méritos políticos, la supresión de la validación de conocimientos y de la pérdida tanto de la disciplina industrial como comercial. Con ello, desde el decenio de 1930 los ferrocarriles estatales se desplazaran hacia atrás en sus servicios cuando la economía avanzaba hacia adelante (Kuntz y Riguzzi 1996, Guajardo, Salas y Velázquez 2010, Guajardo y Riguzzi 2013).

La dificultad para caracterizar los formatos históricos indica la diversidad de orígenes y de tareas que pueden, en todo caso, distinguirse desde un núcleo básico indicado por Millward (2005), en el sentido de que la moderna empresa pública se gesta en el siglo XIX durante la Revolución Industrial por la necesidad ineludible de regular, coordinar y definir derechos de las infraestructuras de las nuevas áreas urbanas, para la producción de bienes en masa y para la construcción de redes. Esto se dio en cinco grandes subconjuntos de fenómenos en donde el Estado participó por:

1. El consumo de servicios en masa como agua potable, gas, transporte, comunicaciones, telégrafo, ferrocarriles que escalaron hacia redes de mayor alcance.

2. La forja de vínculos entre gobiernos e infraestructuras que obligaron a definir los derechos de vía por la necesaria regulación de las expropiaciones, rutas, tarifas, condiciones y normas de ingeniería, intereses garantizados, subsidios e impuestos entre otros.

3. Lo que podríamos llamar intrusividad y durabilidad de la infraestructura. 
4. La alteración de territorios y ciudades requirió definir derechos de propiedad y de paso, junto con definir fuertemente los límites administrativos.

\section{La necesidad de la coordinación de redes.}

Lo anterior para llevarse a cabo debió adoptar tres formatos muy generales: 1) empresa pública localizada en un departamento de gobierno como correos, telégrafos y ferrocarriles; 2) como establecimiento público, como ocurrió en Francia después de 1940 con el llamado establecimiento público de carácter industrial y comercial que tenía personalidad civil y autonomía financiera, siendo dirigido por un consejo de administración independiente del gobierno. El otro tipo fue la corporación pública en el Reino Unido, entidad separada legalmente que no está dentro de las leyes que regulan las compañías comerciales; 3) por acciones como sociedad anónima comercial, siendo ejemplos Air France y Lufthansa (Millward 2005).

\section{UN BALANCE DE LAS EMPRESAS PÚBLICAS A FINES DE LA DÉCADA DE 1970}

Lo señalado por Millward (2005) encuentra una estilizada similitud con el balance que en 1979 hicieron el Banco Interamericano de Desarrollo, la Escuela Interamericana de Administración Pública y la Fundación Getulio Vargas de Brasil sobre las empresas públicas en México y América del Sur. Este estudio notable y guía necesaria para conocer el acervo de las empresas públicas antes del neoliberalismo más extremo, destacaba que los gobiernos de la región desde la década de 1950 habían tenido que enfrentar agudos cambios económicos y políticos, ya sea por los efectos de la Segunda Guerra Mundial, por las políticas planteadas por la Comisión Económica para América Latina y el Caribe (CEPAL), por las exigencias de la Alianza para el Progreso o bien por las presiones y necesidades internas, todo lo cual hizo que los gobiernos latinoamericanos buscaran ejercer sus nuevas atribuciones a través de una línea de menor resistencia, dada por la creación de nuevos organismos e instituciones autónomas que asumieron atribuciones que se consideraban como propias de la administración central (Banco Interamericano de Desarrollo et al. 1979: 7). Pero el rápido surgimiento de las empresas públicas provocó una sensación de espanto en el plano doctrinario por la perspectiva de tener un Estado comerciante, por los problemas de compatibilizar los fines de lucro con el interés público, la contradicción entre empresa pública y sociedad privada y un posible conflicto entre "servicio público versus empresa pública". Por ello la empresa pública latinoamericana en su organización y funcionamiento, se alejó de conceptos jurídicos rígidos porque su creación no se había ajustado 
a un proceso planeado, lo cual se reflejaba en la producción de una amplia gama de bienes y servicios en calidad, tamańo, antigüedad, procedencia, heterogeneidad y falta de coordinación. Todo, a través de vías muy diversas para formarse e incorporarse al patrimonio estatal (Banco Interamericano de Desarrollo et al. 1979: 105), pero podían distinguirse las siguientes formas:

1. Empresas a cargo de servicios públicos, tradicionalmente prestados bajo la tutela o por la acción directa del Estado, en especial las relacionadas con el transporte y la energía.

2. Otras actividades pasaron al patrimonio público o fueron creadas por el Estado para ejecutar políticas o planes económicos en determinadas actividades estratégicas, ya sea para orientar una actividad determinada de acuerdo con pautas diferentes a las que dictaría la empresa privada, o bien captar los recursos allí generados. Tal fue la nacionalización de las empresas de estaño en Bolivia, cuyos recursos se canalizaron a través de la obligación impuesta a la Corporación Minera de Bolivia hacia el Banco Central. La segunda situación se refiere a la creación de nuevas empresas; una vez establecida esa actividad, el Estado la mantuvo en su patrimonio, creó una sociedad mixta, o bien la vendió a capitales privados. Un ejemplo fue la conducta de la Corporación de Fomento de la Producción de Chile, creada en 1939, que organizó empresas en las que tuvo participación mayoritaria o minoritaria en ciertos sectores, y en la industria, suscribiendo acciones y suministrando ayuda técnica.

3. Actividades que se incorporaron al Estado como consecuencia de una confiscación. Fue el caso de bienes de empresas o ciudadanos de países en guerra, nacionalizados temporal o definitivamente (como la propiedad alemana durante la Segunda Guerra Mundial) y de bienes de personas o empresas que el gobierno decidió expropiar por diversos motivos.

4. Casos de "nacionalizaciones salvavidas", en las que el Estado compró empresas que ya no eran rentables para la actividad privada. En algunos de esos casos se procuró la continuidad de ciertos servicios o la provisión de insumos necesarios a la comunidad y en otros se protegió a las empresas, socializando las pérdidas o tomando participación en su capital. El caso más notorio fue la nacionalización de ferrocarriles en países en los cuales comenzaron a producirse pérdidas en la explotación. 
Lo anterior en los distintos países de América Latina se concretó en los siguientes tipos: 1) empresa autónoma. Servicio autónomo creado por ley, con personalidad jurídica y con patrimonio e ingresos propios que lleva a cabo actividades típicas de la administración pública que requieren, para su mejor funcionamiento, una gestión administrativa y financiera descentralizada; 2) sociedad de economía mixta. Es una empresa dotada de personalidad jurídica de derecho privado, creada por ley para la explotación de actividades económicas bajo la forma de una sociedad anónima cuyas acciones con derecho de voto pertenecen, en proporción mayoritaria, al Estado o a la entidad de administración indirecta; 3) empresa pública. Entidad dotada de personalidad jurídica de derecho privado, con patrimonio propio y capital exclusivamente del Estado, creada en virtud de una ley para explotar una actividad económica que el Gobierno ha sido llevado a ejercitar en razón de contingencias o por conveniencia administrativa, y que puede convertirse en cualquiera de las formas de derecho (Banco Interamericano de Desarrollo et al. 1979).

\section{LOS TEMAS DEL DOSSIER: NACIONALISMO, INTERNACIONALIZACIÓN, INDUSTRIALIZACIÓN, PRIVATIZACIÓN Y RE-ESTATIZACIÓN}

Los casos que se presentan en este número cubren gran parte de los puntos señalados más arriba, es decir la diversidad de formatos y la multiplicidad de tareas. Ello se inicia con el caso de Uruguay a cargo de Bertino, Mariño, Querejeta, Torrelli y Vázquez en "Cien Años de Empresas Públicas en Uruguay: Evolución y Desempeño”, el cual emplea la noción de Estado Empresario para identificar dos grandes etapas históricas que corresponden a los modelos de desarrollo aplicados en ese país en el siglo XX, una basada en el desarrollo industrial dirigido por el Estado hasta inicios de los setenta, y el segundo modelo, que señalan como liberal, que abarca hasta la actualidad caracterizado por la modificación de los objetivos de las empresas públicas hacia la rentabilidad. Uruguay sigue siendo el país que mantiene un gran acervo público, pero no fue la excepción a la tendencia privatizadora, aunque ello no se acompañó de una reforma completa del Estado como ocurrió en Brasil, aspecto que viene tratado en las colaboraciones de este número.

Muy cercano a Uruguay en escala y en el papel de las empresas públicas se nos presenta Costa Rica, que en Centroamérica se caracteriza por asegurar el acceso a la electricidad, agua, salud y educación a todos los sectores sociales, con indicadores notables de equidad, calidad, acceso y sostenibilidad ambiental. Ejemplo de ello es el Instituto Costarricense de Electricidad (ICE), analizado por Daniel Chavez y Alberto Cortés Ramos, el cual fue creado en 1949, y que a pesar de los procesos de privatización, 
sigue siendo uno de los pilares de un peculiar Estado de Bienestar y de un modelo solidario que ha resistido diversos intentos de privatización. El artículo aporta diversas herramientas de cómo movimientos sociales y partidos políticos costarricenses han logrado frenar la privatización de dicho acervo público.

Los casos anteriores se ubican dentro del ámbito de sus economías nacionales, pero otra característica que presentan algunas empresas públicas contemporáneas es su internacionalización, lo cual tiene una historia previa en los intentos por establecer vínculos de empresa a empresa en una escala regional, ya sea para la cooperación o la comercialización de sus productos. Una experiencia interesante se dio en las décadas de 1930 y 1940, analizada por María Cecilia Zuleta sobre Yacimientos Petrolíferos Fiscales Bolivianos, empresa creada en 1936, que desde su origen llevó a cabo diversas estrategias para vincularse en el terreno técnico, de la producción, transportación y distribución de combustibles con Yacimientos Petrolíferos Fiscales de Argentina (YPF), creada en 1922. La autora considera esta experiencia como un antecedente lejano a la creación de organizaciones multilaterales que abarcaban la negociación de acuerdos bilaterales para lograr una integración ferroviaria, comercial y petrolera. Sin embargo, esos esfuerzos fracasaron por la inestabilidad e inconsistencia de los gobiernos en turno, como también frente a las posibilidades ofrecidas por los Estados Unidos para la cooperación hemisférica.

Brasil el día de hoy se nos presenta con varias experiencias de internacionalización, producto de su proceso particular de privatización, reforma del Estado y búsqueda de aceleración del crecimiento mediante el sector público. Esto es tratado en dos artículos que nos indican el largo camino hacia la internacionalización de sus empresas tanto públicas como privadas a partir del mercado interno. Para entender lo que ocurre en la mayor economía latinoamericana, Frederico Lustosa da Costa y Vítor Yoshihara Miano analizan en su artículo el papel de las empresas públicas en los ciclos de estatización y desestatización en Brasil, considerando su relación con el ajuste fiscal del Estado. Lo tratan en el largo período de 1930 a 2010, en donde distinguen, al igual que lo hacen Bertino, Mariño, Querejeta, Torrelli y Vázquez para Uruguay, dos grandes ciclos, uno caracterizado por el crecimiento cuantitativo de las empresas para fomentar e impulsar el crecimiento económico, y otro abierto en la década de 1980 con cambios económicos e ideológicos que dieron inicio a la privatización con el fin de detener el crecimiento descontrolado del número de empresas estatales, en particular de las empresas industriales. Pero a diferencia de Uruguay en la década de 1990, se dio un amplio movimiento de reforma del Estado que abarcó la privatización y concesión de servicios públicos, 
hasta que en 2003, a partir del gobierno de Luiz Inácio Lula da Silva, se experimentó un retorno a la intervención estatal y al crecimiento en el número de empresas estatales, pero manteniendo el modelo de concesiones ya adoptado.

En el marco anterior se ubica el caso que analizan Armando Dalla Costa, Huáscar Fialho Pessali y Sandra Cristina da Cunha Gonçalves sobre la internacionalización de Petróleo Brasileiro S.A. (Petrobras), empresa creada en la década de 1950, que creció en el mercado interno y que en la década de 1970 comenzó una lenta andadura hacia el exterior, en un contexto de disputa global por el petróleo vía concesiones de explotación, actividades de refinación y distribución. Pasó de una firma que buscaba insumos para una nueva fase, de venta de productos finales y tecnología hacia la explotación en aguas profundas y ultra profundas.

El caso de Argentina, con el cual se cierra este dossier, presenta cambios menos consistentes y bruscos de creación de empresas públicas, cierre, privatización y re-estatización en sintonía con su inestabilidad política y económica. Un primer caso que ilustra esa situación lo trata Cintia Russo, con la industria naval pesada en la Argentina, en particular con los astilleros estatales Río Santiago (ARS) y Talleres Navales Dársena Norte (Tandanor), cuyo origen y desarrollo se dio en alta dependencia con la capacidad del Estado para ejercer un papel como regulador, productor, demandante y proveedor de financiamiento, situación que, a juicio de la autora, abre una agenda no bien cubierta sobre la relación entre las funciones del Estado y el proceso de industrialización. El brusco cambio que se experimentó en la década de 1990, al imponerse la noción del fracaso del Estado como promotor del desarrollo y del crecimiento, condujeron al cierre de astilleros y la casi desaparición de la industria naval. A inicios del siglo $\mathrm{XXI}$, los cambios en las políticas públicas generaron la posibilidad para la recuperación de los astilleros públicos, aunque debe señalarse que dentro de un escenario económico que no termina de definirse consistentemente, a diferencia de Brasil.

Esta característica de cambios bruscos los trata Esteban Serrani sobre la privatización y re-estatización o renacionalización en Argentina de YPF entre 1989 y 2012, explicando las particularidades que explican cómo una de las empresas nacionales más importantes fue completamente privatizada (a contramano de la experiencia regional en México, Venezuela y Brasil), y cómo veinte años después, volvió al dominio estatal con una expropiación que contó con amplio respaldo popular y parlamentario. Parte de la explicación reside en el carácter de las consecuencias de la desregulación y apertura del sector petrolero, así como en el desempeño de la española Repsol que adquirió la casi totalidad de acciones de YPF en 1999. 


\section{CONCLUSIÓN E INVITACIÓN A LA LECTURA}

Los trabajos de este dossier nos señalan claramente que para la década de 1970 se habían acumulado problemas para las empresas públicas de orden financiero, mezcla de objetivos sociales y económicos, cambio tecnológico, pero también las consecuencias por la diversidad de orígenes, la falta de planeación o como lo señalaba Rostow, por un largo proceso de creación de empresas públicas que redefinía constantemente los límites entre lo público y lo privado con el fin de solucionar determinados problemas de las sociedades. Esto condujo a un complejo resultado de historias entreveradas con un telón de fondo cada vez más crítico, dado por la polarización ideológica de la Guerra Fría que en gran parte impulsó la ortodoxia liberal extrema aplicada por gobiernos autoritarios, como el militar de Chile, o civil en México, para acabar con estos organismos públicos que fueron estigmatizados como un peligro para la libertad económica. La desregulación y la privatización desde la década de 1980 implantaron una versión, cuasi oficial, que señaló a las empresas públicas como instituciones ineficientes que debían ser sustituidas por la empresa privada. En cambio una invitación a leer estos artículos permitirá avanzar hacia una visión más comprensiva gracias a las investigaciones profesionales que se presentan en este número. 


\section{REFERENCIAS}

Abel, C. y Lewis C. M. (1985). General Introduction. En Abel, C. y Lewis C.M. (Eds.), Latin America, Economic Imperialism and the State: The Political Economy of the External Connection from Independence to the Present. London: Athlone-University of London.

Banco Interamericano de Desarrollo, Escuela Interamericana de Administración Pública y Fundación Getulio Vargas. (1979). Las Empresas Públicas en América del Sur y México. México: Limusa.

Barenstein, J. (1982). La Gestión de Empresas Públicas en México. México: CIDE.

Belini, C. y Rougier, M. (2008). El Estado Empresario en la Argentina. Conformación y Crisis. Buenos Aires: Manantial.

Botto, M. y Rojo, A. (1996). Entrevista a Albert O. Hirschman sobre su Vida y Obra. Desarrollo Económico, 35 (140), 629-664.

Bouneau, C. y A. Fernandez (Eds.). (2004). L'Entreprise Publique en France et en Espagne, 18e-20e Siecles. Pessac, Bordeaux: Maison des Sciences de L'Homme d'Aquitaine.

Bremmer, I. (2010). The End of the Free Market: Who Wins the War Between States and Corporations? New York: Portfolio.

Camp, R. (1997). Tecnocracia a la Mexicana, "Antecedente de la Democracia". Pensamiento Iberoamericano. Revista de Economía Política, 30, 155-176.

Carrillo Castro, A. (Coord.). (1976). Las Empresas Públicas en México: Su Importancia en el Sector Industrial y Comercial: Bases Jurídicas de su Acción. México: Instituto Nacional de Administración Pública.

Casar, M. A. y Peres, W. (1988). El Estado Empresario en México: ¿Agotamiento o Renovación? México: Siglo XXI.

Christiansen, H. y OECD. (2011). The Size and Composition of the SOE Sector in OECD Countries. OECD, Corporate Governance Working Papers, 5.

Cole, H., Ohanian, L., Riascos, A. y Schmitz, J. A. Jr. (2005). Latin America in the Rearview Mirror, Journal of Monetary Economics, 52 


$$
\text { (1), 69-107. }
$$

Comín, F. y Díaz Fuentes, D. (2004). La Empresa Pública en Europa. Madrid: Editorial Síntesis.

Deane, P. (1993). El Estado y el Sistema Económico. Barcelona: Editorial Crítica.

Drake, P. W. (1997). La Economía Política de los Asesores y Prestamistas Extranjeros en América Latina. Pensamiento Iberoamericano. Revista de Economía Política, 30, 55-85.

Drucker, P. F. (1988). La Innovación y el Empresario Innovador. La Práctica $y$ los Principios. México: Editorial Hermes.

French-Davis, R., Muñoz, O. y Palma, J. G. (1997). Las Economías Latinoamericanas, 1950-1990. En Bethell, L. (Ed.), Historia de América Latina. II, Economía y sociedad desde 1930. Barcelona: Crítica, Cambridge University Press.

Gárate Chateau, M. (2012). La Revolución Capitalista de Chile (19732003). Santiago: Ediciones Universidad Alberto Hurtado.

Grunstein, A. (2008). Perspectivas Gerenciales sobre el Problema Laboral de los Ferrocarriles Nacionales de México en la posrevolución, 1920-1935. TST: Revista de Historia de los Transportes, Servicios y Telecomunicaciones, 14, 42-89.

Guajardo, G. (2007). Tecnología, Estado y Ferrocarriles en Chile, 1850-1950. Madrid y México: CEIICH - UNAM, Fundación de los Ferrocarriles Españoles.

. (2010). Trabajo y Tecnología en los Ferrocarriles de México: Una Visión Histórica, 1850-1950. México: Consejo Nacional para la Cultura y las Artes. Colección El Centauro.

Guajardo, G. y Riguzzi, P. (2013), Railroad Culture and Mobility in Twentieth Century Mexico. En Tinajero, A. y Freeman, J. B. (Eds.), Technology and Culture in Twentieth Century Mexico. Tuscaloosa, Alabama: Alabama University Press.

Guajardo, G., Salas, F. y Velázquez, D. (2010). Energía, Infraestructura y Crecimiento, 1930-2008. En Kuntz Ficker, S. (Coord.), Historia Económica General de México. De la Colonia a Nuestros Días. México: 
El Colegio de México - Secretaría de Economía.

Hirschman, A. O. (1985). El Paso del Autoritarismo en América Latina y la Búsqueda de sus Determinantes Económicos. En Collier, D. (Comp.), El Nuevo Autoritarismo en América Latina. México: Fondo de Cultura Económica.

Klapp, M. (1982). The State-Landlord or Entrepreneur? International Organization, 36 (3), 575-607.

Kuntz, S. y Riguzzi, P. (1996). El Triunfo de la Política sobre la Técnica: Ferrocarriles, Estado y Economía en el México Revolucionario, 1910-1950. En Kuntz, S. y Riguzzi, P. (Eds.), Ferrocarriles y Vida Económica en México 1850-1950. Del surgimiento Tardio al Decaimiento Precoz. Zinacantepec: El Colegio Mexiquense - UAM Xochimilco Ferrocarriles Nacionales de México.

Marichal, C. (2003). Auge y Decadencia de las Empresas Estatales en México, 1930-1980: Algunas Notas sobre la Relación Histórica entre Empresas Estatales y Endeudamiento Externo. Boletín Oficial del Instituto Nacional de Antropología e Historia, 72, 12-21.

Millward, R. (2005). Private and Public Enterprise in Europe: Energy, Telecommunications and Transport, 1830-1990. Cambridge: Cambridge University Press.

Musacchio, A. y S. G. Lazzarini (en prensa). Leviathan Evolving: New Varieties of State Capitalism in Brazil and Beyond. Harvard University Press.

Nelson, R. (2002). The Problem of Market Bias in Modern Capitalist Economies, Industrial and Corporate Change, 11 (2), 207-244.

Ribeill, G. (2004). Entreprises et Services Publics "à la Francaise": Permanences et Ambiguïtés d'un Modèle hybride a l'Epreuve de la Longue Durée. En C. Bouneau y A. Fernandez (Eds.), L'Entreprise Publique en France et en Espagne, 18e-20e siecles. Bordeaux: Maison des Sciences de l'Homme d'Aquitaine.

Rodrik, D. (1996). Understanding Economic Policy Reform. Journal of Economic Literature, XXXIV (1), 9-41. 
Rostow, W. W. (1973). Autoridad Pública y Empresa Privada: Perspectiva Histórica por el Prof. Walt W. Rostow. En Sempere, J. A. (Comp.), Empresa Pública versus Empresa Privada en Economias en Proceso de Desarrollo. IV Semana Económica Internacional. Barcelona: DOPESA. . (2003). Concept and Controversy: Sixty Years of Taking Ideas to Market. Austin: University of Texas Press.

Stiglitz, J. (2003). El Rumbo de las Reformas. Hacia una Nueva Agenda para América Latina. Revista de la CEPAL, 80, 7-40.

The Economist. (2012). New Masters of the Universe. Autor, Special Report: State Capitalism. Disponible en http://www.economist.com/ node/21542925 [01-05-2012].

Toninelli, P. A. (Ed.). (2000). The Rise and Fall of State-Owned Enterprise in the Western World. Cambridge: Cambridge University Press.

Torre, J. C. (1998). El Proceso Político de las Reformas Económicas en América Latina. Buenos Aires: Paidós.

Waterbury, J. (1999). The Long Gestation and Brief Triumph of ImportSubstituting Industrialization. World Development, 27 (2), 323-341.

Williams, D. (1999). Constructing the Economic Space: The World Bank and the Making of Homo Oeconomicus. Millennium. Journal of International Studies, 28 (1), 79-99.

Recibido: 06-05-2013

Aceptación de la versión final: 10-05-2013 